\title{
DESAFIOS PARA UMA POLÍTICA BRASILEIRA PARA REFUGIADOS NO CONTEXTO CONTEMPORÂNEO
}

\author{
César Augusto Silva da Silva ${ }^{1}$
}

Resumo: Este artigo procura verificar o protagonismo das principais instituições políticas que lidam com o tema dos refugiados no Brasil, a partir da centralidade política do Comitê Nacional para Refugiados e da Polícia Federal, por meio de levantamento bibliográfico e entrevistas semiestruturadas com autoridades de fronteira no âmbito da Ciência Política. Os processos decisórios, os procedimentos burocráticos de controle migratório e de segurança do governo brasileiro a respeito do fenômeno do deslocamento forçado de refugiados. Procura identificar as dificuldades institucionais, os limites e os desafios para execução de políticas públicas voltadas aos refugiados. Evidenciando a falta de coordenação, a fragmentação e a pulverização da política migratória como um todo, e da política para refugiados de maneira particular. Conectados com o passado autoritário do país e a manutenção de mecanismos restritivos para inserção local de imigrantes internacionais.

Palavras-chave: Refugiados. Políticas Públicas. Conare. Policia Federal. Direitos Humanos.

Abstract: This article seeks to verify the role of the main political institutions
dealing with refugees in Brazil, from the action of the political centrality of the
National Committee for Refugees and the Federal Police, through a literature review
and interviews with border officials, under the Political Science. Decision-making
processes, the bureaucratic procedures of migration control and security of the
Brazilian government about the phenomenon of forced displacement of refugees.

1 Professor de Direito e Relações Internacionais da Universidade Federal da Grande Dourados (UFGD). 


\begin{abstract}
Seeks to analyze the bureaucracy and procedural mechanisms geared to foreigners regarding refugees. Identifying the institutional difficulties, limits and challenges to the implementation of public policies geared to refugees. Highlighting the lack of coordination, fragmentation and pulverization of migration policy as a whole, and refugee policy in a particular way, connected with the authoritarian past of the country and the maintenance of restrictive mechanisms for local insertion of international migrants.
\end{abstract}

Keywords: Refugee. Public Politics. CONARE. Federal Police. Human Rights.

\section{INTRODUÇÃO}

Observa-se atualmente um aumento exponencial das migrações internacionais em todas as regiões do planeta. Segundo o Relatório da Organização das Nações Unidas para Migração Internacional e Desenvolvimento, do ano de 2013 (ONU, p. 4), existem mais de duzentos milhões de imigrantes internacionais. Ou seja, jamais tantas pessoas residiram fora de seus países de origem como agora, sendo que o continente asiático lidera este processo global, tendo recebido mais de 20 milhões de migrantes entre os anos de 2000 e 2013, podendo ultrapassar o continente europeu em pouco tempo neste tema (ONU, 2013, p. 5).

$\mathrm{E}$ dentre estes imigrantes internacionais que formam o quadro global de mobilidade humana, existem os refugiados. Isto é, aqueles obrigados a se deslocarem de um país para outro ou de uma região à outra por motivos de perseguição racial, religiosa, política, grupo social ou nacionalidade, conforme a Convenção de Genebra da ONU, de 1951. Apesar de formarem uma pequena porção destes movimentos migratórios mundiais, eles transitam cada vez mais de um país para outro ao lado de indivíduos que migram por várias outras razões não relacionadas com o recebimento de proteção contra estas perseguições, acontecendo em geral através de mobilidade irregular. Sendo que hoje por volta de 15,7 milhões de pessoas classificadas deste modo, conforme o mesmo documento da ONU (2013, p. 7).

Esse trabalho caracteriza migração forçada enquanto a necessidade imposta a indivíduos ou grupos inteiros de deixar o local ou país de origem por motivos alheios à sua vontade. Essas causas podem ser de origem econômica, social, desastres naturais, ambientais e outros fatores relevantes que provoquem crises humanitárias. Isto é, situações onde a organização política e social não pode garantir as necessidades básicas indispensáveis de sobrevivência ao todo ou parte de população, e as pessoas são forçadas a migrar, e podem 
vir a se tornar refugiadas, conforme os parâmetros internacionais.

O estudo apresenta enquanto objetivos a visualização da ação política do Estado brasileiro a respeito do tema dos refugiados a partir do funcionamento de suas instituições políticas que lidam com o tema na perspectiva da Lei n. 9.474/1997, o Estatuto dos Refugiados, que incorporou a Convenção de Genebra, de 1951. Os objetivos são perseguidos a partir do ponto de vista dos agentes públicos do Estado, os procedimentos das instituições políticas envolvidas com a questão migratória para reconhecimento da condição de refugiado e a habilidade dos agentes, identificando as dificuldades institucionais e burocráticas para execução de políticas públicas voltadas aos refugiados.

A perspectiva oficial, ou seja, dos agentes públicos envolvidos com a questão, é de fundamental importância para alcançar os objetivos, particularmente dos agentes de fronteira e sua visão a respeito do fenômeno migratório, mais especificamente dos refugiados. Pois, a pesquisa salienta entrevistas com autoridades de fronteira (a Polícia federal) que, por força da lei 9.474/97, são as autoridades que teoricamente primeiro entram em contato com os solicitantes de refúgio. Ou seja, além do levantamento bibliográfico, se utiliza entrevistas semiestruturadas junto aos policiais federais, bem como textos das autoridades que ocupam cargos estratégicos na polí- tica migratória brasileira, particularmente aquela voltada aos refugiados.

Pois, o processo de produção de políticas públicas depende da interação entre o Estado e os agentes presentes na sociedade, que executam esta política (MARQUES, 2013), os ambientes influenciam instituições a respeito da produção de políticas gerais e específicas, das estratégias compartilhadas e das decisões tomadas. Dessa forma, examinamos as instituições políticas envolvidas a partir do protagonismo do CONARE e da Polícia Federal, além da ação da comunidade internacional, por meio do ACNUR.

Ou seja, a interação entre seus representantes, o depoimento de seus componentes, os acordos firmados entre governo, comunidade internacional e sociedade civil organizada, em atuação tripartite, de modo à verificação do processo decisório a respeito de políticas e do ambiente institucional formatado, envolvendo refugiados e solicitantes de refúgio, particularmente relacionado às competências e ações políticas dos agentes de fronteira e às políticas regulatórias para pessoas deslocadas.

O CONARE - o Comitê Nacional para Refugiados enquanto aquele organismo ligado ao Ministério da Justiça e criado pela Lei n. 9.474/1997, é o responsável pelo reconhecimento da condição de refugiado no Brasil. Ao estabelecer uma legislação e uma estrutura institucional, o país compromete-se 
em identificar e receber refugiados, por meio desta instituição submetida à Secretaria Nacional de Justiça e ao Departamento de Estrangeiros do Ministério da Justiça. Em uma estrutura tripartite de atuação, interministerial, composta por membros do governo, da sociedade civil e da comunidade internacional, conforme a legislação.

E nesse sentido, a legislação procura superar desafios para estabelecer políticas públicas voltadas aos refugiados. Tais desafios giram em torno de uma melhor gestão e organização desta instituição que decide a condição de refugiado no país, pois é o maior responsável pela política nacional para o tema. Assim como a respeito da cultura política dos agentes públicos que compõem a entidade e daqueles que fazem o primeiro contato com um solicitante de refúgio nas fronteiras do país, os agentes da polícia federal.

A Polícia Federal é a autoridade de fronteira em que os solicitantes de refúgio precisam fazer suas entrevistas e solicitações a respeito de sua condição, devido sua competência exposta na Constituição Federal de 1988 e na legislação, responsável por exercer as funções de polícia marítima, aeroportuária e de fronteiras. Portanto, evidencia-se a importância dessa instituição enquanto um dos atores políticos mais destacados para a questão migratória nacional.

Examina-se as interações entre os representantes das instituições políti- cas, o depoimento de seus componentes, os acordos firmados entre governo, comunidade internacional e sociedade civil organizada, em atuação tripartite, de modo à verificação do processo decisório a respeito de políticas e do ambiente institucional formatado. O que acaba envolvendo refugiados e solicitantes de refúgio, particularmente relacionado às competências dos agentes de fronteira e às políticas regulatórias para pessoas deslocadas.

$\mathrm{O}$ aumento das migrações internacionais no mundo atual, o desafio das migrações mistas e a virada brasileira em atração internacional para estrangeiros nos últimos anos, tornam esta pesquisa de extrema importância no que tange à montagem de cenários futuros para a inserção brasileira enquanto atuante na cooperação internacional para temas humanitários. E tais desafios passam a ser examinados a seguir, a partir do diagnóstico das questões relativas aos refugiados do ponto de vista das autoridades que lidam com o tema.

\section{DIAGNÓSTICOS DA POLÍTICA PARA REFUGIADOS NO BRASIL: INSTITUIÇÕES E CULTURA POLÍTICA}

Originado dos estudos da ciência política, o conceito de políticas públicas ganhou influência no Brasil ao sublinhar o exame das avaliações, diagnósticos e 
propostas sobre as ações governamentais, de maneira separada das teorias do Estado de modelo europeu. As teorias europeias tinham em seu núcleo central o estudo das instituições políticas e colocavam em segundo plano as análises da produção governamental (SANTOS; PASE, 2011, p. 71).

Por outro lado, com base em estudos empíricos, em indicadores sociais e diagnósticos sobre todos os tipos de problemas da sociedade, as políticas públicas pretendem responder aos desafios políticos e sociais de forma planejada em médio e longo prazo (SANTOS; PASE, 2011, p. 71-72).

Uma política pública não é qualquer ação governamental, que pode ser simples ou passageira enquanto resposta às demandas sociais conjunturais. Uma política pública consiste em um conjunto de ações intencionais e causais, orientadas para a realização de um objetivo específico ou para atingir benefícios públicos, cujo padrão de ação, de instrumentos, de procedimentos e de recursos se reproduz no tempo de maneira constante e coerente (AGUILAR; ASTORGA; FACIO, 2009).

Uma política pública trata de proporcionar soluções duradouras para um problema específico, a partir de estudos precisos com avaliação, análise e proposição (AGUILAR; ASTORGA; FACIO, 2009). Um Estado ou governo nacional por mais democrático que atue, não tem condições de solucionar todos os problemas, e assim, torna-se fundamental o estudo a respeito do processo de tomada de decisões, da participação social, dos recursos envolvidos, das instituições relacionadas, e da cultura política compartilhada pelos membros relevantes de uma maioria de governo que pretende a implantação desta mesma política.

Nesse sentido, é importante salientar a cultura política dos grupos que dominam as tomadas de decisões governamentais. Parte-se do pressuposto de que o conceito de cultura política estabeleceu um campo de conhecimento específico dos estudos da ciência política a partir da obra de Gabriel Almond e Sidney Verba The civic culture: political attitudes and democracy in five countries, ainda na década de 1960 (ALMOND; VERBA, 1989).

Segundo Borba (2005, p. 147-168), as análises desses autores procuravam superar desafios complicados: por um lado, reforçar e justificar a compreensão da supremacia da sociedade norte-americana como padrão a ser seguido pelo resto do mundo. E por outro, promover e justificar a política norte-americana, em contraposição ao modelo soviético e às teorias socialistas e comunistas.

$\mathrm{O}$ que pode ser dito é que em The Civic Culture o conceito de cultura política está circunscrito às atitudes e valores dos cidadãos e das autoridades em relação aos assuntos políticos (BORBA, 2005). Um tema revisitado pelos autores na década de 80 enquanto uma das mais 
contemporâneas temáticas da ciência política (ALMOND; VERBA, 1989). O termo 'cultura política' refere-se, então, às orientações especificamente políticas, às atitudes comportamentais com respeito ao funcionamento do sistema político, seus diversos componentes e os cidadãos no espaço público (BORBA, 2005, p. 147-168).

Estabelecendo importância fundamental tanto à cultura política quanto às instituições para analisar políticas públicas, neste trabalho parte-se também dos pressupostos de Ingleart (2009) a respeito de cultura política, particularmente a mudança de valores. De modo a defender uma abordagem que sirva enquanto instrumental analítico para inquirir as crenças e os valores dos diferentes grupos sociais, incluindo aqueles que ditam políticas públicas governamentais, como no caso das políticas para refugiados, do mesmo modo que a análise sobre as instituições políticas envolvidas no processo.

Neste viés, no caso da política brasileira para refugiados, a legislação aprovada em 1997 estabeleceu critérios e procedimentos para a obtenção e cassação do refúgio, institucionalizou um órgão específico submetido ao Ministério da Justiça para decidir o status de refugiado aos solicitantes, além das chamadas soluções duradouras para o problema. Para assim estabelecer diretrizes políticas para deslocados, articuladas com autoridades de fron- teira e com os Estados-membros da federação. Nestes termos, a Lei $n$. 9.474/1997 é vista enquanto uma política pública para refugiados, propondo o repatriamento em condições seguras, o reassentamento e a inserção local enquanto soluções duradouras.

A Lei n. 9.474/1997 é produto do ambiente e das forças políticas que buscaram a redemocratização do Brasil ao longo da segunda metade dos anos 80 e nos anos 90 . Nesse processo, os governos civis a partir de 1985 tomaram muitas iniciativas voltadas à causa dos direitos humanos em geral, e dos refugiados em particular. Tal como o Programa Nacional dos Direitos Humanos (Decreto n. 1904, de 13/05/1996), sendo um dos primeiros países a estabelecer internamente os planos de metas para cumprir as diretrizes da Declaração e do Programa de Ação de Viena, de 1993, da II Conferência Mundial da ONU (ALVES, 2003; TRINDADE, 2003).

Atribuindo de forma inédita aos direitos humanos o status de política pública governamental, e sem abdicar de uma compreensão integral e interdependente dos direitos humanos enquanto direitos civis, políticos, sociais, econômicos e culturais. E o que incluiria a situação de imigrantes e refugiados no país (BRASIL; PNDH, 1996), os deslocados de maneira forçada de seu país ou região de origem. 
Visto que a II Conferência Mundial de Direitos Humanos havia incorporado as contribuições do ACNUR para o tema dos refugiados, registrado na Declaração e no Programa de Ação de Viena de 1993 (ALVES, 2003, p. 158; TRINDADE, 2003, p. 414-415), a Declaração reafirmava o direito de toda pessoa de buscar e desfrutar asilo contra perseguição em seu país de origem, assim como de retornar, caso cessassem as hostilidades (TRINDADE, 2003, p. 415-416).

Identificava, inclusive, violações maciças de direitos humanos como um dos fatores que levavam ao deslocamento forçado global de pessoas e recomendava desenvolvimento de estratégias globais para abordar causas e efeitos dos movimentos de refugiados e de deslocados de forma geral. Tendo em vista que o fenômeno crescia de importância na agenda política da Organização das Nações Unidas (ALVES, 2003, p. 159).

A Declaração e o Programa de Ação de Viena, ao ressaltar as responsabilidades dos Estados em relação aos países de origem dos deslocados, enfatizavam o enfoque integral de direitos humanos, a importância das soluções duradouras (repatriação voluntária, integração local e reassentamento) e as questões relacionadas aos deslocados internos. Enfatizava a prevenção de situações futuras de refugiados, alertando para o fato de que na época existiam em torno de 18 milhões de refugiados ao redor do planeta (TRINDADE, 2003, p. 414).
Ou seja, foi amplamente reconhecida por esta Conferência Mundial da ONU a relação intrínseca entre o problema dos refugiados, a partir de suas causas principais, os direitos humanos e as migrações forçadas contemporâneas, em etapas sucessivas (TRINDADE, 2003, p. 272). E, assim, muitos dos direitos humanos enunciados na Declaração de Viena que comemorava 44 anos da Declaração Universal de 1948 aplicavam-se aos refugiados e aos imigrantes internacionais em geral.

Evidencia-se, desse modo, o grau de pioneirismo normativo do Brasil, ao incorporar a Declaração e o Programa de Ação no seu Programa Nacional de Direitos Humanos, em 1996, elaborado a partir de debates da Coordenadoria do Programa Nacional, recebendo contribuições de organizações não governamentais, de universidades e de centros de pesquisa sobre a temática (MESQUITA NETO, 2011, p. 269). O projeto do Programa foi debatido na Conferência Nacional de Direitos Humanos, realizado em Brasília, com grupos temáticos que dariam sua contribuição para o conteúdo do programa (MESQUITA NETO, 2011, p. 269-270).

O Programa Nacional dos Direitos Humanos no Brasil foi o primeiro para proteção e promoção dos direitos humanos na América Latina, e o terceiro no mundo (MESQUITA NETO, 2011, p. 269). Estabeleceu objetivos de curto, médio e longo prazo para os refugiados e imigrantes, conforme as citadas diretrizes 
da II Conferência Mundial de Direitos Humanos. E dentre estes objetivos de curto prazo estava o surgimento de uma legislação específica para refugiados, devido à pressão pela chegada de centenas de imigrantes internacionais que solicitavam refúgio no país, advindos de Angola, Libéria, República Democrática do Congo e da antiga Iugoslávia, todos fugindo de guerras civis, no início da década de 1990 (ALVES, 2001).

Dessa maneira, o Programa de Direitos Humanos foi enviado ao Congresso Nacional, em 1996, acompanhando o Projeto de Lei sobre Refugiados, e aconteceram várias reuniões de especialistas para a produção da legislação (BARRETO, 2010, p.19-20). Este projeto de lei, assim, transformou-se na Lei 9.474/1997, colaborando para a aprovação da legislação junto ao Congresso Nacional, a Igreja Católica, através da Cáritas Arquidiocesana de São Paulo e Rio de Janeiro, representantes do ACNUR, assim como a Comissão de Direitos Humanos da Câmara dos Deputados (BARRETO, 2010, p. 19).

Esta legislação, então, criou o CONARE, um órgão deliberativo coletivo, tripartite, interministerial, com representantes do governo, da sociedade civil e da comunidade internacional, que toma suas decisões técnicas e políticas em plenário, deliberando por maioria simples (artigo $16^{\circ}$ ), para reconhecimento de refugiados no país.

Ou seja, é composto por um representante do Ministério da Justiça, que o preside, por um representante das Relações Exteriores, que exerce a vice-presidência, por um representante do Ministério do Trabalho e do Emprego, do Ministério da Saúde e do Desporto, da Educação, do Departamento de Polícia Federal e por uma organização não governamental que se dedique ao trabalho em favor dos refugiados, atualmente a Caritas Arquidiocesana, de São Paulo e do Rio de Janeiro (artigo 14\%).

O Alto Comissariado das Nações Unidas para Refugiados, ACNUR também participa da instituição, somente com direito a voz, mas sem voto. No entanto, exerce grande influência por sua experiência internacional ao lidar com a temática do refúgio, do deslocamento interno e dos apátridas no resto do mundo (ACNUR, 2012, p.14-17). Além da participação recente da Defensoria Pública da União (DPU) apresentando função consultiva desde 2012.

Os valores e a visão de mundo dos representantes da sociedade civil e do organismo internacional, ACNUR, até mesmo pela larga experiência em tratar diretamente com refugiados ao longo de grande parte do século XX, e pelo acúmulo de "know how" em suas trajetórias históricas, buscam a defesa dos regimes internacionais de direitos humanos e a máxima proteção possível aos refugiados e aos solicitantes (ACNUR, 2000). O que inclui a promoção de cursos e capacitações sobre o tema para os demais membros da sociedade civil, para a Polícia Federal e os orga- 
nismos de imprensa, com ênfase nesta visão de mundo.

A representação da sociedade civil no CONARE, a Cáritas Arquidiocesana, vem lidando com a temática do refúgio no Brasil desde pelo menos meados dos anos 70, ainda no período do regime civil-militar que perseguia seus dissidentes e não reconhecia refugiados latino-americanos. Mesmo nesta época, a instituição desenvolvia um trabalho de proteção aos refugiados que chegavam ao Brasil, vindos da Argentina, Uruguai, Chile e Paraguai, ainda que não reconhecidos como tais pelo governo, acumulando grande experiência e conhecimento especializado sobre o assunto (BARRETO, 2010, p. 62-69).

O ACNUR apresenta longa trajetória em defesa de refugiados desde sua criação. Ainda tenha surgido com recursos limitados e somente com mandato de três anos, desenvolveu um consistente trabalho de médio e longo prazo para solucionar os problemas, focando nas chamadas soluções duradouras - repatriação, integração local e reassentamento, desde suas primeiras experiências, na crise da Hungria, em 1956, e a guerra da Argélia, de 1954 a 1962 (ACNUR, 2000). Com longa experiência acumulada, seus funcionários salientam a importância do Brasil para o fortalecimento do tema, solicitando a máxima cooperação pos- sível do país na busca de equacionar os problemas para deslocados, e exortam pela contínua melhoria do CONARE, incluindo aumento de recursos humanos (Informação Verbal) ${ }^{2}$.

Por outro lado, as maiores preocupações com controle migratório, com segurança institucional e o direito coletivo de uma comunidade política em definir quem são ou não seus residentes, em torno de seletividade e de reciprocidade (WALZER, 2003, p. 63-65), parece advir do governo federal e de suas autoridades de fronteira (a Polícia Federal). Por razões ligadas a sua própria função de controle migratório e as prioridades dos agentes de fronteira no combate aos crimes federais, e de que as comunidades também precisam de limites no sentido de parentesco, reciprocidade e auxílio mútuo (WALZER, 2003, p. 65).

$\mathrm{O}$ treinamento policial para questões migratórias ainda possui ênfase e diretrizes no Estatuto do Estrangeiro (Lei 6.815/1980), com suas modificações pontuais ao longo dos últimos 30 anos (VENTURA, 2012). Ainda que o Estatuto dos Refugiados seja uma legislação especial de direitos humanos para uma situação específica relacionada aos estrangeiros perseguidos que podem solicitar refúgio, o foco do treinamento policial está voltado para

2 RAMIREZ, Andrés. Depoimento. (junho de 2011). Vila Velha (ES). Na Universidade de Vila Velha, no II Seminário Cátedra Sérgio Vieira de Mello. 
questões de segurança pública e a segurança nacional (VENTURA, 2012).

Isto é, a ambiguidade da estrutura legislativa brasileira no que se refere aos estrangeiros torna-se evidente, pois mantém duas legislações divergentes em relação ao tema da imigração internacional. Uma é vinculada à doutrina integral dos direitos humanos (Estatuto dos Refugiados); e a outra, à segurança nacional e ao utilitarismo econômico complementar (Estatuto do Estrangeiro). Contribuindo acentuadamente para a obscuridade de tratamento aos solicitantes de refúgio no Brasil por parte das autoridades de fronteira, no caso, a polícia federal (HAMID, 2012).

Como ressalta Hamid (2012, p. 104), ora o tratamento aos refugiados é encarado como uma questão de direitos humanos, ora é vislumbrado como de segurança pública ou de segurança nacional. Praticamente de maneira divorciada de princípios como "em dúvida pró-refugia$d o$ " ou do "non refoulement", denotando as prioridades dos agentes de fronteira em torno dos valores fiscalizatórios mais repressivos (INGLEART, 2009), previstos no Estatuto do Estrangeiro de $1980 \mathrm{e}$ suas atualizações pontuais ao longo de mais de trinta anos.

Como lembra Neto (2005, p. 307), os imigrantes internacionais encontramse encadeados em uma imensa teia global e que estimula a solidariedade entre indivíduos e o crescimento das máfias do tráfico internacional de pessoas, da exploração sexual e arregimentação de trabalhadores em condições precárias. Por outro lado, foca a atenção e as prioridades dos agentes públicos de fronteira para a questão criminal e os ilícitos internacionais.

Os fluxos migratórios internacionais estão interligados com mudanças estruturais dos sistemas econômicos, sociais e políticos dos diversos países, incluindo o Brasil. Além de desastres ambientais e humanitários, não sendo mais possível analisar simplesmente com base em modelos explicativos de "fatores de expulsão" e "fatores de atração" entre nações, tal como lembra o mesmo Neto (2005, p. 307).

A atual maior projeção política e econômica internacional do Brasil sinaliza uma potencialidade para candidatos à imigração e ao refúgio, destacando-se que o país busca desenvolver sua política econômica e social tornando-se atraente para cada vez mais imigrantes internacionais (OLIVEIRA, 2013, p. 117). Neste sentido, a estrutura migratória de serviços e de recursos humanos não acompanha este ritmo de crescimento, estando ausente uma política consistente de modernização e interligação entre as instituições políticas.

Betts, Loescher e Milner (2008), assim como Hathaway (2007), salientam que polícias e agentes de Estado tendem para interpretações normativas restritivas e securitárias para migrações internacionais. O que abrange a prática das autorida- 
des fronteiriças dos países do hemisfério sul, repetindo a linguagem securitária dos países do hemisfério norte no contexto global de criminalização das migrações, evidenciado também no Brasil.

Evidencia-se uma grande necessidade de superação do treinamento restritivo e a visão de mundo da criminalização das migrações internacionais (HATHAWAY, 2007; BETTS; LOESCHER; MILNER, 2008), enquanto somente um caso de polícia, pautado somente nos valores de conservação e reação enquanto cultura política. Visto que uma mudança cultural não é causada somente pela mudança cívica, mas que interage com a evolução econômica, social e política de uma determinada sociedade (INGLEART, 2009, p. 153).

E no Brasil, há um enorme descompasso entre a cultura política (ALMOND, VERBA, 1989) da comunidade de segurança e defesa, ligadas ao pensamento das Forças Armadas e das polícias (inclusive a polícia federal), com foco na estrita segurança nacional e o discurso dominante da sociedade civil organizada e de setores do governo que privilegiam direitos humanos. Tal qual fossem temas excludentes que não se misturam ou com ligações totalmente superficiais (BRASIL; PNDH, 2010, p. 104).

Com a redemocratização do país, o conceito e os estudos de segurança foram relegados ao ostracismo por parte de universidades e por movimentos da sociedade civil (BRASIL; PNDH,
2010, p. 104), pois pareciam remeter ao passado. E sempre ligados à doutrina da segurança nacional do regime militar de 1964, ou mesmo do Estado Novo, de Getúlio Vargas, que praticavam políticas migratórias rígidas e seletivas (CARNEIRO, 2010, p. 230).

E pelo contrário, a segurança é um direito tanto dos indivíduos como um dever do próprio Estado. É importante salientar que o interesse legítimo dos Estados em matéria de segurança é perfeitamente compatível com os regimes internacionais de direitos humanos e de refugiados (MURILLO, 2009, p. 122). $\mathrm{O}$ direito à segurança dos indivíduos encontra-se consagrado na Declaração Universal de 1948 (artigo $3^{\circ}$ ), enquanto que no plano internacional o sistema de Estados fortalece a segurança estatal e ao monopólio legítimo da circulação migratória (TORPEY, 2005, p. 9-30).

O que parece necessário é a aproximação das vertentes teóricas e das análises específicas destas áreas, para estudos compartilhados e interdisciplinares, de modo à difusão de determinadas temáticas de forma adequada, e aproximação de culturas políticas. Não se utilizando o controle migratório por parte dos Estados para prejudicar ou restringir os direitos fundamentais dos refugiados (MURILLO, 2009, p. 122-123), visto que os direitos humanos são transversais, abarcando distintos setores governamentais e da sociedade civil, incluindo a segurança e a defe- 
sa. Pois, políticas públicas eficientes e transparentes para a proteção nacional de refugiados complementam e fortalecem a segurança dos Estados e dos indivíduos, e não o contrário.

A lei brasileira também não apresenta os aspectos relativos a uma integração social e econômica desta população específica, e nem concede voz aos solicitantes de refúgio no órgão em suas deliberações. Delega funções às organizações não governamentais com as quais mantêm convênios: Caritas Arquidiocesana de São Paulo, Rio de Janeiro e Manaus, e o Instituto de Migrações e Direitos Humanos, em Brasília, para que cumpram as funções de integrá-los à sociedade nacional.

O governo federal brasileiro vem aumentando suas ações em favor dos refugiados nos últimos anos, ainda que pontualmente, pela presença de alguns fatores: o aumento quase exponencial das solicitações de refúgio particularmente entre 2010 e 2013, consolidando-se como novo destino de refúgio. Principalmente nos Estados de São Paulo, Rio de Janeiro e Amazonas, em que a chegada cada vez maior de bengalis, libaneses, senegaleses, sírios e colombianos aumenta o número total de solicitantes (MJ, 2013).

Assim como devido aos acordos com o ACNUR para o programa de reassentamento de refugiados, vigente desde 1999 , e a consequente chegada de colombianos e de palestinos reassentados, recebidos pelas atuais entidades conveniadas com agência da ONU: Associação Antônio Vieira (ASAV), em Porto Alegre/RS, instituição conveniada desde 2003, e o Centro de Defesa de Direitos Humanos (CDDH), em Guarulhos/SP (SILVA, 2013, p. 250-251).

Ainda assim, a crítica do ACNUR ao Brasil e seu programa de reassentamento é que se poderia receber muito mais refugiados reassentados, dos programas administrados pela instituição no mundo inteiro (MARTINS, 2011). E não apenas grupos de palestinos, colombianos, dentre outros, que não chegam nem mesmo ao número de quinhentas pessoas reassentadas. Este número, em um universo de 15 milhões de refugiados ao longo da última década no mundo, conforme o último Relatório da ONU para Migração Internacional e Desenvolvimento (ONU, 2013, p. 7), é politicamente irrelevante.

O ex-presidente do CONARE, Luiz Paulo Teles Barreto, em contrapartida, rebateu críticas do órgão em uma conferência internacional em Genebra. Afirmando que o país está muito longe das grandes crises internacionais que produzem deslocamentos forçados e que as fronteiras brasileiras permanecem abertas às solicitações de refúgio (MARTINS, 2011).

O ex-presidente, e o antigo coordenador geral, Renato Zerbini Ribeiro Leão, destacaram o fato de que os 
números e os procedimentos da instituição indicavam que os solicitantes e os refugiados no país, advêm de todas as partes do mundo, não encontrando nenhuma barreira de ordem política, religiosa ou racial para estarem no Brasil (LEÃO, 2007. p. 75).

O que não quer dizer que os solicitantes consigam chegar facilmente ao país, visto que estas migrações específicas são normalmente irregulares, acontecendo sem documentação e em geral envolvendo tráfico de seres humanos (MJ, 2013). Assim, as pessoas que se deslocam desta maneira viajam geralmente em condições precárias, sendo vítimas de exploração de "coiotes", de atravessadores e de abusos sistemáticos.

No entanto, países também longe demais das crises internacionais e relativamente abertos às solicitações de refúgio, tais como o Canadá, Suécia ou mesmo os Estados Unidos, reassentam muito mais e colaboram de forma muito mais consistente com o ACNUR nos programas de soluções duradouras no quesito reassentamento (MARTINS, 2011). O Brasil parece se destacar entre os países considerados emergentes, mas ainda encontra-se longe de ser um "global player" no quesito de cooperação humanitária internacional, devido suas ambições de política externa e questões de "custo-benefício" (DA SILVA, 2010; OLIVEIRA, 2013).
Na relação da política interna com externa, podem ser enquadradas as iniciativas brasileiras para a criação da Declaração e do Programa de Ação do México de 2004, a Declaração de Brasília de 2010, bem como as iniciativas no âmbito do Mercosul, tornando o tema dos refugiados uma questão estratégica para a política externa, particularmente na relação com países de expulsão de refugiados, no sentido exposto por Zolberg, Suhke e Aguayo (1989, p. 273-274).

O orçamento governamental para o tema continua sendo irrelevante, visto que até o ano de 2004 o CONARE não tinha sequer orçamento próprio para suas atividades dependendo dos recursos destinados ao Departamento de Estrangeiros do Ministério da Justiça (LEÃO, 2007, p.73). Desde então, o CONARE apresenta uma pequena linha orçamentária particular do Ministério destinada à instituição, mas comparativamente ainda modesta levando em conta as outras atividades do próprio ministério e as necessidades dos solicitantes e dos refugiados reconhecidos (LEÃO, 2007; LIMA; SIMÕES, 2012).

O Estado de São Paulo, pela sua articulação política e visibilidade nacional, possui um Comitê Estadual para o assunto, assim como uma longa rede de programas sociais que procuram integrar os refugiados na sociedade. No entanto, esta articu- 
lação e capacidade paulista não se reproduz na maioria dos outros estados da federação, com poucos estados-membros apresentando Comitês Estaduais: somente Rio de Janeiro, Rio Grande do Sul e Paraná, até o ano de 2012. O que configura um assunto para enormes discussões quanto à política de refugiados do país, mas cujos desafios centrais parecem focar-se em sua estrutura política - o papel desempenhado pelo Comitê Nacional para Refugiados e pela Polícia Federal.

\section{OS DESAFIOS DA POLÍTICA PARA REFUGIADOS: O CONARE E A POLÍCIA FEDERAL}

O CONARE atualmente apresenta em torno de somente nove funcionários em sua estrutura administrativa, e com grande acúmulo de casos de anos anteriores (Informação Verbal) $)^{3}$. As decisões podem demorar em média quase um ano, permitindo que muitos solicitantes utilizem o instituto do refúgio como meio de permanência no país por outros motivos, mesmo não sendo solicitantes com fundados temores de perseguição ou com históricos de vida que em que se possam reconhecer os quesitos para o refúgio, ainda que exista o desafio das migrações internacionais mistas.

O próprio ACNUR vem sugerindo algumas soluções há muito tempo para o uso abusivo do instituto, não apenas no Brasil, mas em todo o mundo (ACNUR, EXCOM n. 30, 1983; ACNUR, EXCOM n.79, 1996). Por outro lado, a Polícia Federal vêm colocando a problemática de que muito solicitantes se aproveitam do instituto, porque estas autoridades não podem emitir juízo de valor (pelo menos teoricamente), e somente encaminhar os pedidos ao CONARE (ANDREATA, 2012). O que geraria vulnerabilidade às fronteiras do país segundo sua avaliação, denotando uma cultura política de controle migratório mais rigoroso e preocupações com a segurança institucional (ANDREATA, 2012),

Os desafios mais evidentes do CONARE estão ligados à sua gestão e presença mais constante e espalhada no território brasileiro. Conforme os agentes federais, o órgão concentra-se em Brasília, e não está presente em alguns locais estratégicos e evidentes de entrada de solicitantes de refúgio, tais como: os aeroportos internacionais de Cumbica, em Guarulhos, São Paulo, e do Galeão, no Rio de Janeiro

3 FRANCA, Virginius José Lianza da. Depoimento. (Janeiro de 2013). Em Brasília/DF. No Ministério da Justiça. No CONARE. 
(Informação Verbal) ${ }^{4}$. Além dos portos, como em Santos (São Paulo), a malha portuária do Estado do Espírito Santo, ou do Estado do Rio de Janeiro.

Algumas das regiões em que mais entram migrantes e solicitantes de refúgio são os Estados do Ceará, Amazonas e Mato Grosso do Sul, e fundamentalmente pelos Estados de São Paulo e Rio de Janeiro, via aérea e marítima (MJ, 2013). A chegada por São Paulo e Rio de Janeiro ocorre, dentre outros fatores, porque lá se concentram os principais portos e aeroportos do país, além da presença da Caritas Arquidiocesana. Aqueles que atravessam a fronteira terrestre para pedirem refúgio se dirigem em sua maioria onde se encontram a Caritas (São Paulo, Rio de Janeiro e Manaus) ou o Instituto de Migrações e Direitos Humanos, que mantêm os convênios com a instituição.

Desta forma, o maior número de solicitações ocorre exatamente nos Estados de São Paulo, Rio de Janeiro, Distrito Federal e Amazonas. A presença de organizações não governamentais que trabalham com refugiados vem fazendo uma grande diferença e exercendo um papel de relevo na promoção e na difusão da situação dos refugiados, particularmente nas fronteiras, mas ainda evidentemente insuficiente (IPEA, 2013).
A capacidade comunitária e organizativa dos refugiados no sentido de influenciar, participar dos negócios públicos que decidem sua situação é diminuta, tendo em vista que eles pouco influenciam a instituição principal, a não ser pelas entrevistas e relatórios dos responsáveis em levar os casos à Brasília. Ou seja, com pouca capacidade de influência por parte dos governos nacionais e estaduais que os visualiza como objetos de políticas e não como atores principais nos processos decisórios (ALMOND; VERBA, 1989).

O problema se reflete na inserção geral dos refugiados no país em termos de educação, trabalho, moradia e saúde, além das poucas organizações espalhadas pelo país com capacidade social que promovam políticas de integração. Os refugiados de forma geral se deparam com desafios complexos, desde a moradia até a inserção no mercado de trabalho (RODRIGUES; BÓGUS, 2011, p. 112-114). E os caminhos para melhorar a adaptação parecem estar no sentido de incluir os refugiados em programas de políticas sociais do governo, tais como Bolsa Família, Minha Casa Minha Vida, Brasil Carinhoso ou o PROUNI, quando preencherem os requisitos mínimos necessários.

No entanto, tais tentativas vêm sofrendo diversas barreiras administra-

4 PARDI, Luiz. Depoimento (Setembro de 2012). Em São Paulo. Na PUC-SP. Durante III Seminário Cátedra Sérgio Vieira de Mello. 
tivas por parte das outras instituições do Estado, não coordenadas com a temática do refúgio, tais como o INSS e a Caixa Econômica Federal (MILESI, 2012). Além disso, o CONARE foi acionado no Poder Judiciário pelo Ministério Público Federal em relação ao não reconhecimento dos haitianos enquanto refugiados, do mesmo modo que a Defensoria Pública da União (DPU), em São Paulo, acionou judicialmente a instituição de modo a ter acesso aos documentos sobre os solicitantes de refúgio para fazer sua defesa administrativa (Informação Verbal) . $^{5}$

Neste último caso, a iniciativa teve consequências políticas: a aproximação e a assinatura de um Acordo de Cooperação celebrado entre a Secretaria Nacional de Justiça, o CONARE e a Defensoria Pública da União, no ano de 2012. Com o termo de cooperação, os três órgãos atuarão em conjunto para tratar do instituto do refúgio.

O Secretário Nacional de Justiça e atual presidente do CONARE, Paulo Abrão, corroborou que a partir do acordo nenhum refugiado ficará sem apoio para o exercício dos seus direitos e de- veres. "Essa é a mensagem que estamos hoje anunciando. A participação da DPU nos procedimentos do CONARE qualificará ainda mais as nossas decisões". ${ }^{6}$

A parceria deve procurar a capacitação dos servidores públicos da DPU para que possam analisar melhor o trabalho produzido pelo CONARE e pelo Departamento dos Estrangeiros da Secretaria Nacional de Justiça a respeito de refugiados, pelo menos teoricamente. $\mathrm{O}$ acordo prevê que os defensores públicos passarão a prestar apoio jurídico e acompanhar as necessidades dos solicitantes e dos refugiados relacionados aos processos administrativos, e, inclusive, promover as entrevistas com os solicitantes de refúgio. O que poderá se constituir em um importante apoio estratégico ao Grupo de Estudos Prévios (GEP) do CONARE, assim como uma maior logística estrutural para o órgão, tornando as decisões mais rápidas e eficazes ${ }^{7}$.

Visto que a DPU conta ao todo com 58 unidades distribuídas pelo país, e tal capacidade institucional deve auxiliar os solicitantes de refúgio, ainda que também existam graves e sérios problemas de recursos humanos na DPU,

5 ALMEIDA, Paulo Sérgio de. Depoimento. (abril de 2012). No Rio de Janeiro. No Hotel Ipanema. Durante Seminário Direito dos Migrantes - o Novo Estatuto dos Estrangeiros.

6 Disponível em: $<$ http://www.dpu.gov.br/index.php?option=com_content\&view=article\&i$\mathrm{d}=9620$ :dpu-e-conare-firmam-acordos-para-atuacao-junto-a-estrangeiros=-refugiados\&catid215\&Itemid=458>. Acesso em: 15 dez. 2012.

7 Disponível em: $<$ http://www.dpu.gov.br/index.php?option=com_content\&view=article\&i$\mathrm{d}=9620$ :dpu-e-conare-firmam-acordos-para-atuacao-junto-a-estrangeiros=-refugiados\&catid215\&Itemid $=458>$. Acesso em: 15 dez. 14. 
além da falta de estrutura no interior do país (Informação Verbal) ${ }^{8}$. De qualquer maneira, a expectativa geral é de que a análise dos processos pendentes de apreciação no órgão seja acelerada e qualificada com a elegibilidade sendo procedida pelos defensores públicos.

Outro desafio fundamental para a implantação de políticas específicas para os refugiados no Brasil, do ponto de vista das instituições e da cultura política, localiza-se em um dos atores políticos principais no procedimento de encaminhamento e de reconhecimento de refugiados: a Polícia Federal.

A Polícia Federal, responsável pela vigilância nas fronteiras e nos postos de alfândega, aquela que na maioria das vezes realiza o primeiro contato com os solicitantes de refúgio, possui limitados recursos de pessoas e de estrutura para recebimento de estrangeiros em todo o território nacional. Até a década de 90 o Brasil era um país que mais enviava nacionais ao exterior do que recebia imigrantes, pela conjuntura econômica da chamada "década perdida" dos anos 80 , e porque o regime militar exilava muito de seus nacionais e também não aceitava refugiados latino-americanos (CHADE, 2012).

E assim, sua estrutura institucional e de recursos humanos existentes estão claramente defasadas para a recente virada internacional do país, enquanto polo de atração aos estrangeiros e de política para recebimento e reassentamento de estrangeiros, incluindo refugiados e imigrantes de forma geral (CANO, 2006, p. 137-155).

É uma entidade permanente, organizada e mantida pelo governo federal, estruturada em carreira própria, acumulando diversas competências pela Constituição de 1988, dentre elas, a questão de fronteiras, apresentando grande rotatividade de agentes neste setor. O que muitas vezes os impede de obter especialização e de acompanhar mais diretamente a temática do refúgio, assim como os resultados finais das solicitações junto ao CONARE. Segundo o policial Magalhães (2012) é uma das polícias federais com enorme grau de centralização, hierarquização e de acúmulo de competências relativamente a países do tamanho do Brasil.

Como lembra o mesmo Magalhães (2012), o Brasil optou pela centralização das inúmeras atribuições policiais federativas em um único órgão, o Departamento de Polícia Federal. A política de centralizar na mesma instituição todas as funções de um policiamento federativo possui consequências em relação aos agentes públicos componentes, visto que são obrigados a atuar simultaneamente em várias funções,

8 ZACHER, Laura. Depoimento (maio de 2013). Em Porto Alegre. Na Defensoria Pública da União (DPU). 
muitas vezes perdendo-se a oportunidade da especialização das equipes por setor temático.

AAcademia de Polícia Federal tem capacidade de formação de 1,1 mil policiais por ano, apresentando uma instituição relativamente pequena, com cerca de 11.500 policiais, sob o controle do governo federal (MESQUITA NETO, 2011, p. 248). Com este efetivo necessita cumprir todas as funções administrativas e judiciais, o que ocasiona uma alta rotatividade de servidores e falta de especialização nos diversos setores, incluindo o setor migratório.

Ainda que ARANTES (2011, p.113) aponte para o investimento maciço realizado nas últimas administrações (Lula e Dilma Rousseff) mostrando o crescimento da instituição; a renovação e o protagonismo apontados pelo autor focam as carreiras principais da corporação e as operações de combate à corrupção e ao crime organizado. E não para o corpo integral de seus componentes, particularmente o quadro administrativo, e nem para o desempenho relativo à política migratória (ARANTES, 2011, p. 113-114).

O crescimento qualitativo e quantitativo da instituição que são apontados tanto por ARANTES (2011, p. 116-117) como por MESQUITA NETO (2011, p. 390-391), no contexto do Plano Nacional de Segurança Pública, executado a partir do início do século XXI, mostra uma polícia federal bastante aparelhada e renovada, evidenciando decisões po- líticas em realizar estes investimentos desde o início do governo Lula (20032010). Porém, foca seu protagonismo em determinadas competências em seu vasto rol de atribuições, relacionadas às funções de repressão ao crime, segurança pública e combate à corrupção.

A mudança paradigmática dos cursos e treinamentos da policia federal vêm sendo lentas, e conforme surgem novos concursos públicos para reposição de recursos humanos. As alterações nos currículos de treinamento, assim como o foco nos direitos humanos se tornou gradativamente importante, mas ainda pontual, já alertava BARBOSA e DA HORA (2007). Até mesmo em função da novidade da legislação 9.474/1997, em relação à antiguidade da legislação de 1980 e a tradição de controle e ênfase na questão penal por parte da polícia.

Segundo SOUSA LIMA (2012, p. 60), o Plano Estratégico da Polícia Federal até o ano de 2022 apresenta concentração de recursos em poucos programas e atribuições. E não inclui a atividade migratória nas fronteiras e nem mudança de paradigma, apresentando uma falta de integração entre o orçamento e o planejamento estratégico da instituição.

No que tange ao controle regulatório, ainda encontra-se uma relação com gastos orçamentários na modernização do sistema de emissão de passaportes e de controle de tráfego internacional. Porém, não nas atividades de fronteira 
quanto ao controle migratório de pessoas que potencialmente podem solicitar refúgio (SOUSA LIMA, 2012, p. 60).

Além disso, Sousa Lima (2012, p. 63) também desvenda que a harmonia dos processos decisórios da instituição restringe-se à cúpula da entidade, pois, na medida em que as decisões se distanciam dos órgãos centrais, em direção às unidades regionalizadas, há mais falta de informação e frustração de servidores públicos. Tendo em vista que não chegam informações sobre os limites e os desafios orçamentários e quais foram os critérios para a distribuição dos recursos de forma mais clara.

Neste sentido, como não há um critério objetivo, o autor vislumbra o critério político que gera disputas por espaços entre as unidades regionalizadas, pois algumas podem defender seus interesses de forma mais veemente pelo acesso direto à cúpula da instituição. Assim como não surge como prioridade a questão migratória no plano estratégico do órgão até 2022 (SOUSA LIMA, 2012, p. 63).

Os treinamentos, cursos e especializações ligados à doutrina dos direitos humanos de forma geral, e para refugiados em particular, não aparecem como temas centrais. Provavelmente devido às prioridades policiais para as demais funções na área penal: combate ao narcotráfico, aos crimes de lavagem de dinheiro, à corrupção e ao contrabando, além das funções judiciárias junto ao governo federal, reforçando a cultura política de ênfase na questão criminal.

A importância política da corporação policial para a questão migratória de refugiados cresce no sentido de que ela faz parte do CONARE, e necessita estar interligada com os demais atores políticos, na promoção dos direitos dos refugiados, principalmente no que tange aos refugiados identificados e reconhecidos por elegibilidade nas fronteiras. No entanto, a tensão e a ambiguidade de tratamento, relacionado à securitização das migrações internacionais permanece tendo em vista o paradigma do Estatuto dos Estrangeiros, a Lei $\mathrm{n}$. 6.815/1980 (OLIVEIRA, 2006), e seu foco no crime e no utilitarismo.

Em entrevistas estruturadas empregadas aos policiais federais nas regiões Norte e Centro-Oeste do país, que fazem fronteira com os demais países da América do Sul, nos anos de 2011 e 2012, percebemos uma estrutura rudimentar nas delegacias migratórias, com poucos agentes e o foco da instituição evidentemente na questão penal e de segurança (Informação Verbal) ${ }^{9}$. Além de uma alta rotatividade de agentes e falta de percepção quanto ao fenômeno migratório de solicitantes de refúgio, de maneira a diferenciá-los rapidamente de 
criminosos e/ou imigrantes econômicos ou ambientais.

De forma geral, a entidade é responsável pela prevenção e repressão ao tráfico internacional de entorpecentes, pelas funções de polícia judiciária do governo, e também é responsável pelas funções de polícia marítima, aeroportuária e de fronteiras, conforme a Constituição Federal (artigo 144). Segundo estimativas da própria corporação, a Polícia Federal necessita de milhares de novos profissionais para atuar nas áreas de fronteira seca, para reposição de aposentadorias e para estar capacitada para os grandes eventos internacionais que o Brasil deverá sediar (NOBRE, 2012).

Nos últimos anos, mais de duzentos servidores deixaram seus postos gradativamente, além da deflagração de greves e paralisações por melhores salários. E a tendência será que até meados de 2016 devem ser cerca de 1.100 pessoas aptas a parar de trabalhar por terem atingido os pré-requisitos para solicitar aposentadoria (NOBRE, 2012). A instituição que conta com mais de 11 mil policiais e 2.650 profissionais da área administrativa, apresenta quase $14 \%$ deste efetivo com mais de 50 anos de idade. Some-se a isto o fato de que muito poucos agentes apresentam cursos de especialização em migração internacional ou direitos humanos (NOBRE, 2012).

Ou seja, seu efetivo, com carências estruturais e humanas, deve cumprir todas as funções constitucionais em um território de oito milhões de metros quadrados, com cento e noventa milhões de habitantes. Com quase 17 mil km de fronteira terrestre com dez diferentes países sul-americanos, e que nem sempre são estáveis e com controle migratório funcionando eficazmente (DA SILVA, 2010).

Acrescente-se a isso a necessidade de superação de uma cultura política autoritária (ALMOND; VERBA, 1989; INGLEART, 2009) herdeira dos períodos de regimes de exceção. O que configura assim um quadro global bastante desalentador no que tange à uniformização e consistência da política migratória brasileira.

\section{CONSIDERAÇÕES FINAIS}

Do ponto de vista da promoção de políticas públicas, o tema dos refugiados no Brasil apresenta uma legislação própria desde 1997 que estabelece uma instituição diretamente responsável pelo processo decisório governamental. Uma organização ligada diretamente ao Ministério da Justiça: o CONARE como órgão de decisão jurídico-político para elegibilidade de refugiados, composto por membros de vários outros ministérios, além de representantes da sociedade civil e da comunidade internacional, de forma tripartite e interministerial, mas não paritário, em seu processo decisó- 
rio, com a centralidade do Ministério da Justiça, que o preside.

Os desafios mais destacados da política nacional de refugiados estão diretamente ligados à ampliação dos recursos institucionais, humanos e financeiros do CONARE. Assim como relacionados à sua democratização, com participação de outras instituições relevantes, além da transformação da cultura política dos agentes públicos de fronteira no atendimento aos solicitantes.

O CONARE apresenta algumas iniciativas no sentido de dinamizar e qualificar o atendimento aos solicitantes de refúgio e aos próprios refugiados presentes no país. Medidas em torno de parcerias com a Defensoria Pública da União, por exemplo, de modo a responder aos desafios de celeridade nas decisões e qualificação nos procedimentos.

Os limites apontam para o fato de que a instituição convive com uma legislação global para política migratória, o Estatuto dos Estrangeiros de 1980, que é contraditória com as diretrizes da doutrina integral dos direitos humanos, consagrada no Estatuto dos Refugiados de 1997. Sendo que tal legislação ainda serve como parâmetro para o tratamento aos imigrantes internacionais que são recebidos e identificados nas fronteiras do país, pelas autoridades migratórias.

Ou seja, na identificação dos solicitantes e dos refugiados por elegibilidade, enquanto uma política regulatória ambivalente ora voltada para a seguran- ça pública e a segurança nacional, com a criminalização de migrações internacionais mistas, ora para uma questão de direitos humanos, voltada para proteção dos vulneráveis.

Esta ambiguidade e falta de clareza da política migratória está ligada diretamente ao longo processo político de redemocratização do país, de forma lenta, segura e gradual e a herança autoritária, advinda desde o regime do Estado Novo de Getúlio Vargas. Se por um lado houve a redemocratização de instituições políticas, por outro, manteve-se práticas e estruturas legislativas restritivas herdeiras dos períodos ditatoriais da história republicana. Agravado pela falta de consenso entre os diferentes atores políticos que lidam com a temática migratória, para uma mudança global de legislação e de práticas políticas nos últimos trinta anos, particularmente quanto aos agentes de fronteira.

Dito de outra maneira, uma política migratória regulatória cujas restrições foram aceleradas pelo contexto global de securitização de migrações internacionais desde os atentados terroristas na Europa e Estados Unidos, no início do século XXI. E ao mesmo tempo está informada pela doutrina da segurança nacional e do utilitarismo econômico que marcou os períodos ditatoriais brasileiros, essencialmente nos anos 30 (o Estado Novo) e nos anos 60 (Regime Militar). E que enxergavam o estrangeiro globalmente enquanto inimigo e subversivo, sendo 
bem vindo somente aquele que traziam complementação econômica.

A Polícia Federal cresceu de importância política na questão migratória desde a Constituição de 1988, desempenhando um papel estratégico na recepção, acolhimento e saída de imigrantes e refugiados do território brasileiro, pois é a autoridade de fronteira com os quais os solicitantes primeiro entram em contato, ao lado das organizações não governamentais.

É a instituição onde os recém-chegados devem fazer suas primeiras manifestações de solicitação de refúgio, apresentando uma importância estratégica capital. Possui sérias limitações estruturais e institucionais quanto ao controle dos solicitantes de refúgio, no que tange aos seus recursos humanos para as fronteiras, portos e aeroportos internacionais do país.

Ela parece não estar preparada e nem possuir estrutura administrativa e recursos humanos suficientes para receber e acolher deslocados forçados nas fronteiras brasileiras, solicitantes de refúgio ou não, diferenciando-os rapidamente dos imigrantes econômicos no contexto das migrações internacionais mistas, além de treinamento baseado ainda no Estatuto dos Estrangeiros de 1980. Embora desempenhem um papel estratégico, estando presente no CONARE, apresentam um alto grau de rotatividade no setor migratório e falta de especialização temática, além da ausência do instituto do refúgio em seu plano estratégico de longo prazo.

Assim, contribuindo decisivamente para um divórcio entre o discurso oficial brasileiro de legislação avançada em matéria de refúgio, de historicidade de hospitalidade e cordialidade, do respeito à tolerância e à diversidade, e à prática política dos órgãos de controle, registros e classificações de estrangeiros, incluindo refugiados. No sentido de restrição ostensiva, burocratização demasiada e soluções paliativas para regularização de estrangeiros no país.

A prática mais corriqueira e constante do poder público tem sido delegar funções à sociedade civil organizada, as organizações não governamentais, para o cumprimento da responsabilidade de integrar refugiados no mercado local. E que tais instituições consigam superar as barreiras impostas pelo próprio Estado, através de suas outras instituições públicas pulverizadas, não coordenadas com o instituto do refúgio.

Apesar do discurso oficial do governo de que somos um país historicamente hospitaleiro, com uma legislação avançada sobre refugiados, elogiada pela comunidade internacional, tal discurso não se reflete na prática contemporânea em relação ao recebimento e acolhimento de solicitantes de refúgio nos estritos parâmetros das convenções internacionais e de sua própria legislação.

Se por um lado houve avanços institucionais, legislativos e de inserção nos 
regimes internacionais de proteção de direitos humanos em relação ao passado ditatorial do país; por outro, a prática continua descoordenada e pulverizada entre diversos atores políticos, com medidas paliativas na política migratória de forma geral, e medidas pontuais na política regulatória e de inclusão de refugiados, de forma particular.

A política brasileira para refugiados vislumbra a lei 9.474/1997 e o CONA$R E$ enquanto mecanismos capazes de promover políticas públicas de inclusão dos poucos refugiados presentes no país. Mas, continuam existindo barreiras relativas ao exercício pleno da cidadania e o não reconhecimento da situação dos refugiados no país por parte de institui-

\section{REFERÊNCIAS}

ACNUR. A Situação dos Refugiados no Mundo - cinquenta anos de ação humanitária. Trad. Isabel Galvão. Almada: Artes Gráficas, 2000. . A Year of Crises - Global Trends 2011. Geneva: UNHCR, 2012.

. Recomendação EXCOM, 30

(XXXIV), - Comitê Executivo - $34^{a}$ Sessão, 1983.

. Recomendação EXCOM, 79

(XLVII), - Comitê Executivo- $47^{a}$ Sessão, 1996.

ANDREATA, Rafael Potsch. Desembarque de quem quer refúgio não é apropriado. Disponível em: www. ções públicas do Estado. Assim como a falta de criação de instituições estaduais e municipais articuladas para capacitar e incluir os refugiados na cidadania e superar visões de mundo de criminalização destes deslocados.

Ou seja, a desarticulação das políticas voltadas aos refugiados resta evidente pela combinação de uma série de fatores. A soma de uma legislação migratória global desatualizada com um treinamento de agentes policiais de fronteira focada na segurança nacional e no utilitarismo econômico, com a ausência dessas instituições políticas locais espalhadas pelo país, torna a situação dos refugiados e solicitantes no país, algo extremamente desesperador.

conjur.com.br. Acesso em: $15 \mathrm{dez}$. 2012.

AGUILLAR; ASTORGA; LIMA FACIO. Que son y para qué sirven las politicas públicas? In: Contribuciones a las Ciencias Sociales, sept. 2009. Disponible en: www.eumed. net/cccss/05/aalf.htm.

ALMOND, Gabriel. VERBA, Sidney. The civic culture: political attitudes and democracy in five nations. Princeton: Princeton University Press, 1989.

. The civic culture revisited. Londres: Sage Publications, 1989. 
ARANTES, Rogério Bastos. Polícia Federal e Construção Institucional. In: AVRITZER, Leonardo. FILGUEIRAS, Fernando. (Orgs.). Corrupção e Sistema Político no Brasil. Rio de Janeiro: Civilização Brasileira, 2011, p. 99-132, 2011.

ALVES, José Augusto. Relações Internacionais e Temas Sociais - A Década das Conferências. Brasília: IPRI, 2001.

. Direitos Humanos como Tema Global. São Paulo: Perspectiva, 2003.

BARBOSA, Luciano Pestana; DA HORA, José Roberto Sagrado. A Polícia Federal e a Proteção Internacional dos Refugiados. Brasília: ACNUR Brasil, 2007.

BARRETO, Luiz Paulo Teles Ferreira. (Org.). Refúgio no Brasil - A Proteção Brasileira aos Refugiados e seu Impacto nas Américas. Brasília: Ministério da Justiça, 2010.

BETTS, Alexander; LOESCHER, Gill; MILNER, James. The United Nations High Commissioner for Refugees (UNHCR) - the politics and practice of refugee protection into the twenty-first century.London/ New York: Routledge, 2008.

BORBA, Julian. Cultura Política, Ideologia e Comportamento Eleitoral: alguns apontamentos teóricos sobre o caso brasileiro In: Opinião Públi$c a$, Campinas, v. XI, n. 1, março de 2005, p. 147-168.
BRASIL. Constituição. Texto Constitucional promulgado em 5 de outubro de 1988. Brasília: Senado Federal, 2012.

. Programa Nacional de Direitos Humanos - PNDH3. Brasília: SDH/PR, 2010. .Decreto. $n$ 1.904, de 13 de maio de 1996. PNDH. Brasília: Ministério da Justiça, 1996.

. Lei 9.474, de 22 de julho de 1997 - Define mecanismos para a implementação do Estatuto dos Refugiados de 1951, e determina outras providências.

. Lei 6.815, de 19 de agosto de 1980 - Define a situação jurídica do estrangeiro no Brasil, cria o Conselho Nacional de Imigração.

CANO, Ignacio. Políticas de Segurança Pública no Brasil: Tentativas de Modernização e Democratização versus a Guerra contra o Crime. In: Revista Internacional de Direitos Humanos. n. 5. Ano 3, 2006. p. 137-155.

CARNEIRO, Maria Luiza Tucci. Cidadão do Mundo - o Brasil diante do Holocausto e dos judeus refugiados do nazifascismo (1933-1948). São Paulo: Perspectiva/Fapesp, 2010. DA SILVA, Francisco Carlos Teixeira. Política de Defesa e Segurança do Brasil no Século XXI: Um Esboço Histórico. IPEA - Instituto de Pesquisa Econômica Aplicada. 2010. 
DE ALMEIDA, Paulo Sérgio. Migração e Tráfico de Pessoas. Cadernos de debates - refúgio, migrações e cidadania, Brasília, v.7, n.7, 2012. p. 43-50.

HAMID, Sônia Cristina. (Des) Integrando Refugiados: Os Processos do Reassentamento de Palestinos no Brasil. Brasília/DF, UNB, 2012. Tese (Doutorado em Antropologia). Universidade Nacional de Brasília, Instituto de Ciências Sociais.

HATHAWAY, James C; NEVE, R. Alexander. Making International Refugee Law Relevant Again: a proposal collectivized and solution-oriented protection. Harvard Human Rights Journal, v.6, Spring, 1997, pp. 1-76.

INGLEART, Ronald; WELZEL, Christian. Modernização, Mudança Cultural e Democracia. - a sequência do desenvolvimento humano. Trad. Hilda Maria Lemos Pantoja Coelho. São Paulo: Francis, 2009.

IPEA - Cooperação Brasileira para o Desenvolvimento Internacional. Brasília: Instituto de Pesquisa Econômica Aplicada/Agencia Brasileira de Cooperação, 2013.

LEÃO, Renato Zerbini Ribeiro. $O$ Reconhecimento dos Refugiados pelo Brasil - Decisões Comentadas do CONARE. Brasília: Conare/ACNUR Brasil, 2007.

LIMA, João Brígido Bezerra. SIMÕES, Gustavo da Frota. Programas de Suporte a Refugiados, Asilados e
Apátridas no Brasil: uma abordagem exploratória. In: $1^{\circ}$ Seminário Nacional de Pós-Graduação de Política Externa. Brasília: 12 e 13 de julho de 2012.

MAgalHãeS, Luiz Carlos. As Policias Federais Estadunidenses e o Nosso Departamento de Polícia Federal. Disponível em: $<\mathrm{http}: / / \mathrm{www}$. ambito-juridico.com.br/site/index. php?n_link=revista_artigos_leitura \&artigo_id $=4408>$. Acesso em: 15 dez. 2012.

MARTINS, Rui. Brasil acolhe poucos refugiados? Disponível em: www. sinditamaraty.org.br. Acesso em: 12 dez.2011.

MARQUES, Eduardo. As Políticas Públicas na Ciência Política. In: MARQUES, Eduardo; FARIA, Carlos Aurélio Pimenta de. (Orgs.). A Política Pública como Campo Multidisciplinar. São Paulo/Rio de Janeiro: Unesp/Fiocruz, 2013.

MESQUITA NETO, Paulo de. Ensaios sobre Segurança Cidadã. São Paulo: Quartier Latin/Fapesp, 2011.

MILESI, Rosita. Refugiados e Direitos Humanos. Disponível em: <http:// www.migrante.org.br/IMDH/ControlConteudo.aspx?area $=001 \mathrm{c} 1 \mathrm{~b} 0 \mathrm{~d}-$ 181f-450a-83fb-47915ce5f2eb>. Maio de 2012. Acesso em: 25 jul. 2012.

MINISTÉRIO DA JUSTIÇA. Pesquisa ENAFRON - Diagnóstico Sobre Tráfico de Pessoas nas Áreas de 
Fronteira. Brasília: Secretaria Nacional de Justiça, 2013.

MURILLO, Juan Carlos. Os Legítimos Interesses de Segurança dos Estados e a Proteção Internacional de Refugiados. In: Revista Internacional de Direitos Humanos. Ano 6, n. 10, São Paulo - jun. 2009.

NETO, Helion Póvoa. A Criminalização das Migrações na Nova Ordem Internacional. In: NETO, Helion Povoa; FERREIRA, Ademir Pacelli (Orgs.). Cruzando Fronteiras Disciplinares - um panorama dos estudos migratórios. Rio de Janeiro: Revan, 2005, p. 297-309.

NOBRE, Letícia. Polícia Federal precisa de 4.174 servidores até 2014. Disponível em: <http://sosnconcurseiro.jconcursos.uol.com.br>. Acesso em: 10 dez. 2012.

ONU. International Migration and Development. Report of Secretary General. New York: General Assembly, 2013.

OLIVEIRA, Márcia Maria de. A Mobilidade Humana na Tríplice Fronteira: Peru, Brasil e Colômbia. Revista Estudos Avançados, v. 20, n. 57, p. 183-196, ago. 2006.

OLIVEIRA, Ivan Tiago Machado. Política Externa e Negociações Comerciais no Brasil. Revista Política Externa, v. 21, n.3, jan./fev. 2013, p. 113-132.

RODRIGUES, Viviane Mozine; BÓGUS, Lúcia Maria Machado. Os
Refugiados e as Políticas de Proteção e Acolhimento no Brasil: História e Perspectivas. Revista Dimensões, v. 27, 2011, p. 101-114. SANTOS, Everton. PASE, Hemerson Luiz. Capital Social e Políticas Públicas na América Latina. In: BAQUERO, Marcelo (Org.). Cultura(s) Politica(s) e Democracia no Século XXI na América Latina. Porto Alegre: UFRGS, 2011.

SILVA, César Augusto S. da. Política Brasileira para Refugiados (19982012). Porto Alegre, UFRGS, Tese (Doutorado em Ciência Política). Universidade Federal do Rio Grande do Sul, 2013.

SOUSA LIMA, Rafael. Orçamento Público Como Instrumento de Gestão no Nivel das Organizações Governamentais: o Caso da Policia Federal. Curso de Mestrado em Administração Pública. Escola Brasileira de Administração Pública e de Empresas da Fundação Getúlio Vargas. Rio de Janeiro, 2012.

TORPEY, John. L'invention du Passeport: États, citoyenneté et surveillance. Paris: Bélin, 2000.

TRINDADE, Antonio Augusto Cançado. Tratado Internacional de Direitos Humanos. v. 1. 2. ed. Porto Alegre: Fabris Editor, 2003.

WALZER, Michael. Esferas da Justiça - uma Defesa do Pluralismo e da Igualdade. Trad. Jussara Simões. São Paulo: Martins Fontes, 2003. 
VENTURA, Deisy. Qual a Política Migratória do Brasil? Disponível em: $<$ http://www.diplomatique.org.br/ artigo.php?id=1121>. Acesso em: 13 dez. 2012.

ZOLBERG, Aristide R; SUHRKE, Astri; AGUAYO, Sergio. Escape From Violence - conflict and the refugee crisis in the developing world. New York: Oxford University Press, 1989.

\section{ENTREVISTAS}

ALMEIDA, Paulo Sérgio de. Depoimento (maio de 2012). Presidente do Conselho Nacional de Imigração, Representante do Ministério do Trabalho e do Emprego no CONARE. Entrevista concedida no Hotel Ipanema, Rio de Janeiro. Durante Seminário Direito dos Migrantes, promovido pela Secretaria Nacional de Justiça.

FRANCA, Virginius José Lianza da. Depoimento (janeiro de 2013). Coordenador Geral do CONARE. Entrevista concedida no Ministério da Justiça, em Brasília/DF, Sala do CONARE.
PARDI, Luiz Depoimento (setembro de 2012). Delegado federal lotado no Aeroporto Internacional de Cumbica, em Guarulhos/SP. Entrevista concedida na PUC-SP, em São Paulo. Durante o III Seminário Cátedra Sérgio Vieira de Mello.

POLICIAIS FEDERAIS (10 Entrevistados) lotados nas delegacias migratórias de Rio Branco (Acre), Manaus (Amazonas), Porto Velho (Rondônia). Depoimentos (outubro de 2011/maio de 2012). Entrevistas concedidas em Rio Branco -AC, Manaus - AM e Porto Velho-RO nas Delegacias de Polícia Migratória. RAMIREZ, Andrés Alfonso. Depoimento (junho de 2011). Representante do ACNUR no Comitê Nacional para Refugiados (CONARE). Entrevista concedida na Universidade de Vila Velha/ES. Durante II Seminário Cátedra Sérgio Vieira de Mello.

ZACHER, Laura. Depoimento (maio de 2013). Socióloga da Defensoria Pública da União, lotada em Porto Alegre. Entrevista concedida na Defensoria Pública da União. Em Porto Alegre/RS. 